\title{
Ar-Ge Harcamaları ve Patent Başvuru Sayısının Ekonomik Büyüme Üzerindeki Etkileri: OECD Ülkeleri Üzerine Bir Uygulama*
}

\section{The Impacts of Research and Development Expenditures and Number of Patent Application on Economic Growth: An Application on OECD Countries}

\author{
Doç. Dr. Süleyman Emre Özcan - Arş. Grv. Pınar Özer
}

Başvuru Tarihi: 14.07.2017

Kabul Tarihi: 11.08.2017

\section{Öz}

Bu çalışma, seçili 23 OECD ülkesi (Ekonomik İşbirliği ve Kalkınma Örgütü) için 1995 - 2013 yıllık verilerini kullanarak, Ar-Ge harcamalarının ve patent başvuru sayılarmın ekonomik büyüme üzerindeki etkisini panel veri analiziyle test etmeyi amaçlamaktadır. Çalışmada değişkenler arasındaki uzun dönemli ilişkilerin varliğ Westerlund Panel Eşbütünleşme testleriyle araştırılmış ve panel bazında değiş̧kenler arasındaki uzun ve kısa dönemli katsayılar Ortalama Grup Tahmincisi (MGE) ve Havuzlanmış Ortalama Grup Tahmincisi (PMGE) yöntemleriyle tahmin edilmiştir. Ekonometrik analiz sonucunda panel genelinde değerlendirildiğinde Ar-Ge harcamaları ve patent başvuru sayılarının ekonomik büyüme üzerindeki uzun dönem etkisi istatistiki olarak anlamlı ve pozitiftir. Buna karşın kısa dönem katsayıları pozitif fakat istatistiki olarak anlamlı değildir.

Anahtar Kelimeler: Ar-Ge Harcamalarl, Ekonomik Büyüme, Havuzlanmış Ortalama Grup Tahmincisi (PMGE),Patent Başvuru Sayısı, Westerlund Panel Eşbütünleşme Testi

\begin{abstract}
This study aims to investigate the effect of $R \& D$ expenditures and number of patent application on economic growth using panel data analysis and 1995 - 2013 annual data for selected 23 OECD (Economic Cooperation and Development Organization) countries. In the study, the existence of long-run relationships between variables was investigated by Westerlund Panel Cointegration Tests and long and short term coefficients between panel-based variables were estimated by Mean Group Estimator (MGE) and Pooled Mean Group Estimator (PMGE). As a result of econometric analysis, the long - run effect of $R \& D$ expenditures and the number of patent application on economic growth is positive and statistically significant when evaluated panelwide. On the other hand, the short-run coefficients are positive but not statistically significant.
\end{abstract}

Keywords: $R \& D$ Expenditures, Economic Growth, Pooled Mean Group Estimator (PMGE), Number of Patent Application, Westerlund Panel Cointegration Test

\footnotetext{
* Bu çalışma 2017 yılında Dumlupınar Üniversitesi Sosyal Bilimler Enstitüsünde kabul edilen "AR-GE Harcamaları, Patent Başvuru Sayısı ve Ekonomik Büyüme: OECD Ülkeleri Üzerine Bir Uygulama” başlıklı Yüksek Lisans tezinden türetilmiştir.

Doç. Dr. Süleyman Emre Özcan, Celal Bayar Üniversitesi İ̈BF İktisat Bölümü, semre.ozcan@dpu.edu.tr Arş. Grv. Pınar Özer, Dumlupınar Üniversitesi İİBF İktisat Bölümü, pinar.ozer@dpu.edu.tr
} 


\section{Giriş}

İktisadi büyümenin temel göstergesi olarak kabul edilen kişi başına reel gelir, ülkeler arasında çok büyük farklılıklar göstermektedir. Örneğin, Dünya Bankası 2015 yılı verilerine göre Burundi ülkesi 206 USD kişi başına reel gayrisafi yurtiçi hasıla rakamı ile dünyanın en düşük kişi başına gelir düzeyine sahip ülkesi olmuşken Lüksemburg 106.408 USD ile dünyanın en yüksek kişi başına gelir düzeyine sahip ülkesi olmuştur. ABD'de bu rakam 50.000 USD üzerinde iken diğer birçok ülkede ise kişi başına gelir düzeyi bu rakamın çok daha altındadır. Ülkelerin gelir düzeyindeki farklılıklar sahip oldukları fiziksel sermaye, işgücü miktarı, teknolojik düzey, doğal kaynaklar, beşeri sermaye, girişimcilik kültürü, kurumsal yapı ve hükümet politikaları gibi birçok faktörden kaynaklanmaktadır. Bir ülkenin büyümesini belirleyen bu faktörler ekonomik büyümenin kaynakları olarak bilinmektedir.1980'lerden itibaren küresel ekonomideki gelişmeler ve artan rekabete bağlı olarak büyümenin kaynağ üzerinde daha fazla durulmaya başlanmıştır.

Yeniliğin geleneksel ölçütleri Ar-Ge harcamaları ve patentlerdir. Fakat son zamanlarda çeşitli kurumlar tarafından yeniliği ölçmek için farklı yöntemler geliştirilmiştir: a) Yenilik Anketleri, b) Avrupa Birliği İnovasyon Karnesi (EIS), c) Küresel İnovasyon Endeksi (GII). Fakat EIS ve GII’ye ilişkin verilerin yıllık bazda zaman aralığı yetersiz olduğu için ampirik çalışmalarda çoğunlukla yeniliğin geleneksel ölçütleri, Ar-Ge ve patent faaliyetlerine ilişkin veriler kullanılmaktadır.

İnovasyon göstergelerinden Ar-Ge ve patent faaliyetlerinin büyüme ile önemli bir ilişkisi vardır. Ar-Ge faaliyetlerinden kaynaklanan yenilikler, maliyetlerin ve enerji tüketiminin azaltılmasına, yeni pazarlara girişe, ürün kalitesinin iyileştirilmesi ile yeni ürün ve üretim yöntemlerinin geliştirilmesine olanak sağlaması sonucunda şirketlerin ve ülkelerin rekabet gücünü artırarak ekonomik büyümeye katkı sağlamaktadır. Patentler ise buluş yapan kişilere yasal olarak fikirlerinin ticari değerlerini ve bu yüzden ortaya ç1kacak karı koruduğunu garanti eder. Bununla birlikte patent süreci ile buluş yapan kişi buluşunun tüm detaylarını ifşa eder. Patent başvurusunda buluşla ilgili verilen detaylar ile ortaya çıkan çok fazla miktarda bilgi serbestçe kullanılabilir hale gelir. Bu sayede diğer insanlar buluşa konu olan fikirden ilham alarak başka yararlı ürünler yaratma fırsatına sahip olurlar (Miller vd., 2012, s.102). Sonuç olarak, her iki durumda da patentler buluş (yeni fikirlerin yaratılması) ve inovasyonu (yeni fikirlerin başarılı ticari uygulaması) teşvik etmesi kanalıyla ekonomik büyümeye olumlu yönde yansiyacaktır.

$\mathrm{Bu}$ çalışmada; Ar-Ge harcamaları ve patent başvuru sayısının ekonomik büyüme üzerindeki etkisinin ortaya koyulması amaçlanmaktadır. Bu çalışmanın mevcut literatüre katkısı iki şekildedir: (i) Çalışmada her ülkedeki farklı regülasyonların patent başvuru sayısı üzerindeki etkilerini izole etmek için ABD Marka ve Patent Ofisine (USPTO) yapılmış patent başvuru sayısı verisi kullanılmış ve (ii) Yeni ekonometrik yöntemlerden - Westerlund Panel Eşbütünleşme Testi, Havuzlanmış Ortalama Grup, Ortalama Grup Tahmincileri- yararlanılmıştır.

\section{İnovasyon- Ekonomik Büyüme İlişkisine Yönelik Literatür}

\section{Teorik Literatür}

Modern büyüme teorileri henüz ortaya çımadan önce Adam Smith, David Ricardo ve Karl Marx'in fikirlerinde teknolojik değişmeler (yeni makinalar) önemli bir yer tutmaktaydı. Teknolojinin ekonomik büyümedeki rolünün farkında olmalarına karşın uzun dönem iktisadi büyüme ile ilişkisini sağlıklı bir şekilde açıklayacak büyüme kuramları geliştirmemişlerdir (Coombs vd., 1987, s.139; Gürak, 2006, s.11).

Joseph Schumpeter, inovasyonun ekonomik büyümenin itici gücü olarak önemini vurgulayan ilk ekonomist olmuştur. Uzun dönem ekonomik büyümeyi konu alan çalışmalarında özellikle inovasyonun oynadığı kritik rol ve onu etkileyen faktörlere odaklanarak ekonomiyi sosyoloji ve tarihten gelen anlayışlarla harmanlamıştır. İnovasyonun ve dolayısıyla ekonomik büyümenin itici gücü olarak girişimcilere odaklanan J. Schumpeter, inovasyon ve ekonomik büyümeyi mikroekonomik düzeyde değerlendirmiştir. Görüşleri zamanında çok fazla yankı uyandırmamasına karşın 1980'lerde yer edinmeye başlayan, teknolojik gelişmeyi modele dâhil etmenin önemini kabul eden içsel büyüme modelleri - özellikle Aghion ve Howitt $(1992,1999)$ - Schumpeter'den etkilenerek 
oluşmuştur (Sveningsen, 2015, s.14 - 15). 1980'lerin sonu 1990'ların başında ortaya çıkan içsel büyüme modelleri Schumpeter'in yenilik hakkındaki görüşleri etrafında şekillenmiştir. Schumpeter (1983, s. 17 - 18)'e göre yenilik, yeni bir ürünün veya yeni bir üretim yönteminin ortaya çıkmasını, yeni bir pazara açılmayı, yeni tedarik kaynağına sahip olmayı ya da herhangi bir yeni endüstriyel örgüt biçimlerinin belirmesini kapsayan faaliyetlerden oluşur.

İkinci Dünya Savaşı̉nın hemen akabinde geliştirilen Harrod - Domar Büyüme Modeli özellikle iktisadi planlama yapanlar arasında popüler olmuştur. Harrod (1939) ve Domar (1946) birbirlerinden bağımsız olarak benzer iki model geliştirmiştir. Geliştirdikleri bu model, 1940’larda iktisadi düşüncede hâkim olan John Maynard Keynes'in iyi bilinen makroekonomik modelinin basit genişletilmiş haliydi (Van den Berg, 2001, s.106).Çağdaş büyüme modelleri arasında yer alan bu modelde yeni teknolojinin ekonomik büyümeye katkısı incelenmemiş; teknolojik gelişme sermaye-çıktı oranını etkileyebileceği kanısıyla modele dolaylı olarak girmiştir.

Solow öncesi Neo-Klasik büyüme modelinde teknolojik gelişme olmaksızın bir ekonominin kişi başına çıktısını, sermaye birikimi ile arttırmanın azalan verimler ilişkisi, insanların tasarruf etme arzusu, nüfus artış hızı ve sermaye stokunun yıpranma oranı hesaba katıldığında sinırlı olduğu sonucuna ulaşılmıştır. Bu yüzden uzun dönemde kişi başına sürekli büyümeyi açıklayabilmek için teknolojik gelişme büyüme modeline dâhil edilmeliydi. R. Solow, modern büyüme modeline teknolojik gelişmeyi ilk dâhil eden ekonomisttir. Solow (1957) büyüme modeli, ekonomik büyümeyi sadece sermaye birikimi ve işgücü olmak üzere iki faktörle açıklayan Harrod - Domar modelinin genişletilmiş biçimidir. Bununla birlikte, Harrod - Domar modeli zayıf ampirik bulgulara maruz kalırken Solow, büyüme modelinin daha gerçekçi koşullarla uyumlu hale gelmesi için varsayımlarının sağlamlılı̆̆ını geliştirmiştir: İlk olarak, Harrod-Domar modelinde sabit olduğu varsayılan teknoloji zamanla gelişme kaydetti. Bu gelişme teknoloji ile sermaye yo- gunnluğu arasında ayrım yapmayı gerektirdi. Solow modelinde bu unsurlar sırasıyla dışsal ve içsel olarak kabul edilmiştir. Ona göre teknolojik gelişme işgücü ve sermaye artışı dışında kalan ekonomik büyümenin açıklanamayan kısmıdır. İkinci olarak, Harrod Domar modelinde emek ve sermayenin sabit olduğu varsayımı Solow modelinde yerini emek ve sermayenin tam ikame olduğu varsayımına bırakmıştır

Neoklasik büyüme modellerinden teknolojik gelişmeli Solow (1957) modelinin aksine içsel büyüme modelleri, teknolojik gelişmeyi cennetten düssen meyve şeklinde yorumlamamaktadır. Ekonomik büyüme sürecinde içselleştirilen teknolojik gelişme piyasanın yönlendirdiği bilinçli yatırım kararları sonucunda ortaya çıar ve teknolojik yeniliklerin ortaya çıkmasında Ar-Ge faaliyetlerinin rolü yadsınamaz. Ar-Ge faaliyetlerine dayanan içsel büyüme modellerinde Ar-Ge sektörünün sürekli ekonomik büyümeyi sağlamada önem arz ettiğinin ve Ar-Ge sektöründeki beşeri sermaye ve bilgi stokunun desteklenmesi gerektiğinin altı çizilmiştir. Konuyla ilgili literatürde birçok çalışma olmasına karşın, Ar-Ge temelli büyüme modelleri esas olarak Romer (1990), Grossman ve Helpman (1989, 1990, 1993, 1997) ile Aghion ve Howitt $(1992,1999)$ tarafından geliştirilen modeller üzerine inşa edilmiştir.

\section{Ampirik Literatür}

İçsel büyüme modellerine yönelik literatürdeki ampirik çalışmaların birçoğu genellikle inovasyon göstergesi Ar-Ge değişkenlerinin toplam faktör verimliliği veya ekonomik büyüme üzerindeki etkisini test etmeyi içerirken literatürdeki daha az çalışma patentin büyüme üzerindeki etkisini araştırır (Schmookler, 1966; Devinney, 1994; Crosby, 2000; Sinha, 2008; Saini ve Jain, 2011; Josheski ve Koteski, 2011; Guo ve Wang, 2013; Işık, 2014). Bu çalışma literatürde sıklıkla yararlanılan her iki inovasyon göstergesini - patent ve Ar-Ge verilerini- kullanarak bu iki değişkenin uzun ve kısa dönemde ekonomik büyüme üzerindeki etkilerini araştıracaktır. Bu doğrultuda yapılacak olan ekonometrik analizle ilgili ampirik literatür Tablo l'de verilmektedir. 
Tablo 1. İnovasyon - Ekonomik Büyüme İlişkisine Yönelik Ampirik Literatür

\begin{tabular}{|c|c|c|c|c|c|}
\hline Eserler & Temel Değişkenler & Dönem & Ülke(ler) & Yöntem & Sonuç \\
\hline Crosby (2000) & $\begin{array}{c}\text { Reel GSYİH, çalışan } \\
\text { başına GSYİH, patent } \\
\text { başvurusu sayısı }\end{array}$ & 1901-1997 & Avustralya & VAR & $\begin{array}{l}\text { Kısa dönemde patent ve } \\
\text { büyüme arasında negatif ilişki } \\
\text { varken uzun dönemde } \\
\text { patentin ekonomik büyüme ve } \\
\text { işgücü verimliği üzerindeki } \\
\text { etkisi pozitiftir. }\end{array}$ \\
\hline $\begin{array}{c}\text { Samimi ve } \\
\text { Alerasoul (2009) }\end{array}$ & $\begin{array}{l}\text { GSYİH, Ar-Ge } \\
\text { harcamaları }\end{array}$ & $2000-2006$ & $\begin{array}{l}30 \text { Gelişmekte Olan } \\
\text { Ülke }\end{array}$ & $\begin{array}{l}\text { Sabit Etkiler } \\
\text { Modeli }\end{array}$ & $\begin{array}{l}\text { İstatistiki olarak anlamlı } \\
\text { pozitif etki }\end{array}$ \\
\hline Peng (2010) & $\begin{array}{l}\text { GSYİH, Ar-Ge } \\
\text { harcamalar1 }\end{array}$ & $1987-2007$ & Çin & $\begin{array}{l}\text { Engle Granger } \\
\text { Eşbütünleşme, } \\
\text { Granger } \\
\text { Nedensellik } \\
\text { Testi } \\
\end{array}$ & $\begin{array}{l}\text { İstatistiki olarak anlamlı } \\
\text { pozitif etki }\end{array}$ \\
\hline $\begin{array}{l}\text { Genç ve Atasoy } \\
\text { (2010) }\end{array}$ & $\begin{array}{l}\text { Kişi başına düşen } \\
\text { GSYİH, Ar-Ge } \\
\text { harcamaları }\end{array}$ & $1997-2008$ & 34 ülke & $\begin{array}{c}\text { GMM } \\
\text { Nedensellik } \\
\text { Testi }\end{array}$ & $\begin{array}{l}\text { Ar-Ge'den büyüme doğru tek } \\
\text { yönlü nedensellik iliş̧isi }\end{array}$ \\
\hline Saini ve Jain (2011) & $\begin{array}{l}\text { Patent başvuru sayısı, } \\
\text { GSYİH artış oranı }\end{array}$ & $2000-2009$ & 9 Asya Ülkesi & $\begin{array}{l}\text { Regresyon } \\
\text { Analizi }\end{array}$ & $\begin{array}{l}\text { Yalnızca } 4 \text { Asya Ülkesi - } \\
\text { Singapur, Tayland, Japonya } \\
\text { ve Vietnam- için istatistiki } \\
\text { olarak anlamlı pozitif etki }\end{array}$ \\
\hline $\begin{array}{l}\text { Josheski ve Koteski } \\
\text { (2011) }\end{array}$ & $\begin{array}{c}\text { Çeyreklik GSYİH, } \\
\text { çeyreklik patent }\end{array}$ & $1963-1993$ & G7 Ekonomileri & ARDL & $\begin{array}{l}\text { Uzun dönemde pozitif kısa } \\
\text { dönemde negatif ilişki }\end{array}$ \\
\hline $\begin{array}{l}\text { Mehran ve Reza } \\
\text { (2011) }\end{array}$ & $\begin{array}{l}\text { GSYİH artış oranı, Ar- } \\
\text { Ge harcamalarının } \\
\text { GSYİH'ye oranı }\end{array}$ & - & $\begin{array}{l}\text { Gelişmiş Ülkeler } \\
\text { (OECD) ve } \\
\text { Gelişmekte Olan } \\
\text { Ülkeler }\end{array}$ & $\begin{array}{c}\text { Havuzlanmış } \\
\text { EKK, Sabit } \\
\text { Etkiler, Rassal } \\
\text { Etkiler } \\
\end{array}$ & $\begin{array}{l}\text { İstatistiki olarak anlamlı } \\
\text { pozitif etki }\end{array}$ \\
\hline $\begin{array}{l}\text { Gülmez ve } \\
\text { Yardımcığlu } \\
\quad(2012)\end{array}$ & $\begin{array}{l}\text { Kişi başına düşen } \\
\text { GSYİH, kişi başına } \\
\text { düşen Ar-Ge } \\
\text { harcamaları }\end{array}$ & $1990-2010$ & 21 OECD Ülkesi & $\begin{array}{c}\text { Pedroni, Kao } \\
\text { Eşbütünleşme } \\
\text { Testleri, } \\
\text { DOLS, } \\
\text { FMOLS } \\
\end{array}$ & $\begin{array}{l}\text { İstatistiki olarak anlamlı } \\
\text { pozitif etki }\end{array}$ \\
\hline $\begin{array}{l}\text { Doruk ve } \\
\text { Söylemezoğlu } \\
(2014)\end{array}$ & $\begin{array}{l}\text { Kişi başına düşen milli } \\
\text { gelir artışı, Ar-GE } \\
\text { harcamalarının } \\
\text { GSYİH içindeki payı }\end{array}$ & $2000-2007$ & $\begin{array}{l}22 \text { gelişmekte olan } \\
\text { ülke }\end{array}$ & $\begin{array}{l}\text { PCSE ve GMM } \\
\text { modeli }\end{array}$ & $\begin{array}{l}\text { İstatistiki olarak anlamlı } \\
\text { pozitif etki }\end{array}$ \\
\hline $\begin{array}{c}\text { Altıntaş ve Mercan } \\
\text { (2015) }\end{array}$ & $\begin{array}{c}\text { Reel GSYİH artış } \\
\text { oranı, kişi başına Ar- } \\
\text { Ge harcamaları artış } \\
\text { oranı }\end{array}$ & $1996-2011$ & 21 OECD Ülkesi & $\mathrm{AMG}$ & $\begin{array}{l}\text { İstatistiki olarak anlamlı } \\
\text { pozitif etki }\end{array}$ \\
\hline $\begin{array}{l}\text { Freimane ve Balina } \\
\qquad(2016)\end{array}$ & $\begin{array}{l}\text { Çalışan başıına düşen } \\
\text { GSYİH, Ar-Ge } \\
\text { harcamalarının } \\
\text { GSYİH içindeki payı }\end{array}$ & $2000-2013$ & AB Ülkeleri & GMM & $\begin{array}{l}\text { İstatistiki olarak anlamlı } \\
\text { pozitif etki }\end{array}$ \\
\hline $\begin{array}{c}\text { Özşahin ve } \\
\text { Gömleksiz (2016) }\end{array}$ & $\begin{array}{l}\text { Kişi başına GSYİH } \\
\text { artışı oranı, Ar-Ge } \\
\text { harcamalarının } \\
\text { GSYİH içindeki payı }\end{array}$ & $2000-2014$ & $\begin{array}{l}11 \text { Yükselen Piyasa } \\
\text { Ekonomisi }\end{array}$ & $\begin{array}{l}\text { Westerlund } \\
\text { Durbin - } \\
\text { Hausman } \\
\text { Eşbütünleşme } \\
\text { Testi ve AMG } \\
\end{array}$ & $\begin{array}{l}\text { İstatistiki olarak anlamlı } \\
\text { pozitif etki }\end{array}$ \\
\hline Tunalı (2016) & $\begin{array}{l}\text { Ar-Ge harcamaları ve } \\
\text { alt bileşenlerinin } \\
\text { GSYİH içindeki payı, } \\
\text { reel GSYİH artış oranı }\end{array}$ & $1981-2012$ & 18 OECD Ülkesi & MGE, PMGE & $\begin{array}{l}\text { Yalnızca kamu kesimi Ar-Ge } \\
\text { harcamaları istatistiki olarak } \\
\text { anlamlıdır. Kısa dönemde } \\
\text { etkisi negatif iken uzun } \\
\text { dönemde pozitiftir. }\end{array}$ \\
\hline Li ve Jiang (2016) & $\begin{array}{l}\text { Ar-Ge harcamaları, } \\
\text { verilen patent sayıs1, } \\
\text { GSYİH }\end{array}$ & $1995-2014$ & Çin & $\begin{array}{l}\text { Regresyon } \\
\text { Analizi }\end{array}$ & $\begin{array}{l}\text { İstatistiki olarak anlamlı } \\
\text { pozitif etki }\end{array}$ \\
\hline $\begin{array}{l}\text { Dam ve Y1ld1z } \\
\quad(2016)\end{array}$ & $\begin{array}{l}\text { GSYİH değişim oranı, } \\
\text { kamu ve özel sektör } \\
\text { toplam Ar-Ge } \\
\text { harcamalarının GSYH } \\
\text { içindeki payı, yerli } \\
\text { yabancı toplam patent } \\
\text { sayıs1 } \\
\end{array}$ & $2000-2012$ & $\begin{array}{l}\text { BRICS-TM } \\
\text { Ülkeleri }\end{array}$ & Panel EKK & $\begin{array}{l}\text { İstatistiki olarak anlamlı } \\
\text { pozitif etki }\end{array}$ \\
\hline Türedi (2016) & $\begin{array}{c}\text { Kişi başına GSYİH, } \\
\text { Ar-Ge harcamalarının } \\
\text { GSYİH'ye oranı, } \\
\text { toplam patent başvuru } \\
\text { sayısı } \\
\end{array}$ & 1996-2011 & 23 OECD Ülkesi & GMM & $\begin{array}{l}\text { İstatistiki olarak anlamlı } \\
\text { pozitif etki }\end{array}$ \\
\hline
\end{tabular}




\section{Veri Seti ve Ekonometrik Yöntem}

\section{Veri Seti}

Toplam Ar-Ge harcamalarının ve USPTO'ya yapılmış toplam faydalı patent başvuru sayılarının ekonomik büyüme üzerindeki etkisinin panel veri analizi yöntemi ile belirlenmesi amaçlanan bu çalışmada Türkiye'nin de dâhil olduğu 23 OECD ülkesine ait 1995-2013 dönemini kapsayan seriler kullanılarak ekonometrik analiz yapılmışıı. Parametre tahmininin sağlamlılığını arttırmak için panel veri analizi yeterli düzeyde örneklem büyüklügüne dayanmalıdır. $\mathrm{Bu}$ yüzden çalışmada zaman aralığ (19 yıl) ve ülke sayıs1 (23 OECD ülkesi) gözlem sayısını (437) mümkün olduğunca maksimum kılacak şekilde belirlenmiştir.

Çalışmada ekonomik büyüme göstergesi olarak 2010 yılı sabit fiyatlarla kişi başına düşen gayrisafi yurtiçi hâsıla verisi kullanılmıştır. İnovasyonu neyin ölçtüğü literatürde tartışma konusu olmuştur. Fakat birçok çalışma inovasyonu ölçmek için patent başvuru sayısı ve gayrisafi yurtiçi Ar-Ge harcamaları verilerini kullanır. Literatürdeki çalışmalara benzer olacak şekilde bu çalışmada da inovasyon göstergesi olarak 2010 y1lı sabit fiyatlarla toplam Ar-Ge harcamaları ile USPTO'ya yapılmış faydalı patent başvuru sayısı verileri kullanılmıştır. Bununla birlikte patent başvuru verisini kullanmanın yarattığı bir problem vardır; o da ülkeler arasında patentleme sürecinin aynı olmamasıdır. Diğer bir deyişle ülkeler patent vermede farklı yöntemleri izler. Bu problemi çözmek için USPTO'dan elde edilen verilerden faydalanılmıștır. Bununla beraber patent başvurusu yapıldığı yıl ile patentin alındığı yıl arasındaki zaman aralığı çok uzun olabileceğinden alınan patent sayısı yerine patent başvuru sayısı verisi kullanılmıştır.

Ekonometrik analizde dikkate alınan ülke grupları, değişkenler ve veri kaynaklarına ilişkin detaylı bilgi Tablo 2 ve Tablo 3'te sunulur.

Tablo 2. Ekonometrik Analize Dâhil Edilen Ülkeler

\begin{tabular}{|c|c|c|c|c|}
\hline Avusturya & Fransa & İtalya & Polonya & Türkiye \\
\hline Belçika & Almanya & Japonya & Portekiz & İngiltere \\
\hline Kanada & Macaristan & Güney Kore & Slovakya & ABD \\
\hline Çek Cumhuriyeti & İrlanda & Meksika & Slovenya & \\
\hline Finlandiya & İsrail & Hollanda & İspanya & \\
\hline
\end{tabular}

Tablo 3. Veri Tanımları ve Kaynaklar

\begin{tabular}{|c|c|c|c|}
\hline Değişken & Kisaltma & Tanım & Kaynak \\
\hline $\begin{array}{l}\text { Kişi } \quad \text { Başına } \\
\text { Düşen Gayrisafi } \\
\text { Yurtiçi Hâsıla }\end{array}$ & kbgsyih & $\begin{array}{l}\text { Gayrisafi yurtiçi hâsıla belli bir zaman periyodunda bir ülkenin } \\
\text { sınırları içerisinde üretilen nihai mal ve hizmetlerin parasal } \\
\text { değeridir. Kişi başına düşen gayrisafi yurtiçi hâsıla ise gayrisafi } \\
\text { yurtiçi hasılanın ülkedeki toplam kişi sayısına bölünmesiyle } \\
\text { bulunur. Çalışmada } 2010 \text { sabit fiyatlarla hesaplanmış kbgsyih } \\
\text { tercih edilir ve ekonometrik analiz kısmında değişkenin logaritması } \\
\text { alınmış değerleri kullanılır. }\end{array}$ & OECD \\
\hline $\begin{array}{l}\text { Gayrisafi Yurtiçi } \\
\text { Ar-Ge } \\
\text { Harcamaları } \\
\text { (milyon \$) }\end{array}$ & $\mathrm{rd}$ & $\begin{array}{l}\text { Bir ülkedeki yerleşik firmalar, araştırma merkezleri, üniversiteler } \\
\text { ve devlet laboratuvarları vb. tarafından yürütülen Ar-Ge çalışmaları } \\
\text { üzerine yapılan harcamaları ifade eder. Yurtdışı kaynaklar } \\
\text { tarafından finanse edilen Ar-Ge harcamaları bu hesaplama } \\
\text { içerisinde dâhil edilirken yerel ekonomi dışında gerçekleştirilen Ar- } \\
\text { Ge faaliyetleri için fonlar bunun dışında tutulur. Çalışmada } 2010 \\
\text { sabit fiyatlarla hesaplanmış rd tercih edilir ve ekonometrik analiz } \\
\text { kısmında değişkenin logaritması alınmış değerleri kullanılır. }\end{array}$ & OECD \\
\hline $\begin{array}{l}\text { Toplam faydalı } \\
\text { patent başvuru } \\
\text { sayısı }\end{array}$ & pat & $\begin{array}{l}\text { "Ícat için patent" olarak da bilinen faydalı patent, yeni ve faydalı } \\
\text { bir süreç, makina, üretim veya madde bileşimi veya bunlarla ilgili } \\
\text { yeni ve faydalı gelişmeler için verilen patentlerden biridir. Faydalı } \\
\text { patent sahipleri başvuru tarihinden itibaren } 20 \text { yıl boyunca diğer } \\
\text { kişilerin icadı yapmasına, kullanmasına veya satmasına engel olur. } \\
\text { Son yıllarda USPTO tarafından verilen patentlerin yaklaşı \% } 090 \text { '1 } \\
\text { faydalı patentler sınıfında yer alır (USPTO, 2016). Ekonometrik } \\
\text { analiz kısmında değişkene ait logaritmik değerler kullanılır. }\end{array}$ & USPTO \\
\hline
\end{tabular}




\section{Ekonometrik Yöntem}

\section{Panel Veri Modellerinde Yatay Kesit Bağımlılığının Test Edilmesi}

Panel veriye ilişkin literatürün geneline bakıldığında panel veri setlerinde önemli ölçüde yatay kesit bağımlılığı olduğu ortak kanısına varılmıştır. Yatay kesit bağımlılı̆̆ı, ortak şoklar ve hata teriminin bir parçası olan gözlemlenmeyen unsurlar veya mekânsal bağımlılık sonucu ortaya çıkabilir. Bununla birlikte 1990'lardan beri gittikçe artan ekonomik ve finansal entegrasyon yatay kesit birimleri arasında güçlü korelasyona yol açmaktadır (De Hoyos ve Sarafidis, 2006, s. 482). Bu açıklamalar doğrultusunda yatay kesit ba$\breve{g} ı$ lilığı testi panel veri modellerini tahmin etmede oldukça önem arz eder. Bu çalışmada $\mathrm{N}>\mathrm{T}$ olduğu için Friedman (1937), Frees (1995) ve Pesaran (2004) tarafından geliştirilen yatay kesit bağımlılık testlerinin kullanılması uygun bulunmuştur.

\section{Pesaran (2004) Yatay Kesit Bağımlılığı Testi}

Yatay kesit bağımlılı̆̆ını test eden istatistiklerden biri Breusch ve Pagan (1980) tarafindan geliştirilen Lagrange Multiplier (LM) istatistiğidir. Breusch ve Pagan (1980) tarafından geliştirilen LM testi zaman boyutu T, N'den daha büyük olduğu durumda $(T>N)$ ya da $\mathrm{N}$ sabit ve $\mathrm{T} \rightarrow \infty$ iken kullanılması daha uygundur. Fakat yatay kesit sayısı fazla ve zaman sonlu olduğunda $(\mathrm{T} \square \mathrm{N}) \mathrm{c}$ ise LM test istatistiği arzulanan istatistiki özelliklere sahip olmaz (De Hoyos ve Sarafidis, 2006, s.483). Bu yüzden $\mathrm{N}$ fazla olduğu durumda bu testin kullanılması uygun değildir. Bu problemin üstesinden gelmek için Pesaran (2004) hem T>N hem de $\mathrm{N}>\mathrm{T}$ durumlarında geçerli olan aşağıdaki LM test istatistiğini geliştirmiştir (Nazlıoğlu vd., 2011, s.6618; İlgün, 2016, s.76):

$$
\mathrm{CD}_{1}=\sqrt{\frac{1}{\mathrm{~N}(\mathrm{~N}-1)}} \sum_{\mathrm{i}=1}^{\mathrm{N}-1} \sum_{\mathrm{j}=\mathrm{i}+1}^{\mathrm{N}}\left(\mathrm{T}-\widehat{\mathrm{p}}_{\mathrm{ij}}{ }_{\mathrm{ij}}-1\right)
$$

$\mathrm{T} \rightarrow \infty$ ve $\mathrm{N} \rightarrow \infty$ ile birlikte yatay kesit bağımlılığının olmadığ sıfır hipotezi altında test istatistiği asimptotik standart normal dağılıma sahiptir. $\mathrm{CD}_{1}$ test istatistiği LM test istatistiğinin barındırdığı eksikliklerinin üstesinden gelmesine karşın N/T $\rightarrow \infty$ olduğu durumda $\mathrm{CD}_{1}$ testi önemli ölçüde büyüklük bozulması (size distortion) gösterir. $\mathrm{N}$ fazla ve $\mathrm{T}$ az $(\mathrm{T}<\mathrm{N})$ olduğu durumda Pesaran (2004), genel heterojen dinamik modeller ve durağan olmayan modeller dâhil olmak üzere esnek model yapısına izin veren alternatif bir yatay kesit bağımlılığı testini ileri sürmüştür (Sarafidis vd., 2009, s.150):

$$
C D_{2}=\sqrt{\frac{2 T}{N(N-1)}}\left(\sum_{i=1}^{N-1} \sum_{j=i+1}^{N} \hat{p}_{i j}\right)
$$

$\mathrm{T} \rightarrow \infty$ ve $\mathrm{N} \rightarrow \infty$ ile birlikte yatay kesit bağımlılı̆̆ının olmadığı sifır hipotezi altında $\mathrm{CD}_{2}$ test istatistiği asimptotik standart normal dağılıma sahiptir.

\section{Friedman (1937) Yatay Kesit Bağımlıı̆ı̆ı Testi}

Friedman (1937) çarpım-moment korelasyon katsayısı gibi düşünülebilen Spearman’n sıralama korelasyon katsayısına dayanan parametrik olmayan bir test önermiştir. Spearman’n sıralama korelasyon katsayıs1 sıra değerlerinden hesaplanır. $\left(\mathrm{u}_{\mathrm{i}, \mathrm{l}}, \ldots, \mathrm{u}_{\mathrm{i}, \mathrm{T}}\right)$ 'nin sıra değerleri $\left(r_{i, 1}, \ldots, r_{i, T}\right)$ olarak gösterilecek ve ortalama sıra değeri $(T+1 / 2)$ olacak şekilde Spearman'ın sıralama korelasyon katsayısı şu denkleme eşittir:

$r_{i j}=r_{j i}=\frac{\sum_{t=1}^{T}\left(r_{i, t}-\left(T+\frac{1}{2}\right)\right)\left(r_{j, t}-\left(T+\frac{1}{2}\right)\right)}{\sum_{t=1}^{T}\left(r_{i, t}-\left(T+\frac{1}{2}\right)\right)^{2}}$

Spearman'in korelasyon ortalamasına dayanan Friedman istatistiği;

$R_{O R T}=\frac{2}{N(N-1)} \sum_{i=1}^{N-1} \sum_{j=i+1}^{N} \hat{r}_{i j}$

Denklemde $\hat{r}_{i j}$ artıklara ait sıralama korelasyon katsayısının örneklem tahminidir. Büyük $\mathrm{R}_{\mathrm{ORT}}$ değerleri yatay-kesitsel birimler arasında korelasyonun sifirdan farklı olduğunu gösterir. Bununla Friedman, $\mathrm{N}>\mathrm{T}$ için $\mathrm{FR}=\left[(\mathrm{T}-1)\left((\mathrm{N}-1) \mathrm{R}_{\mathrm{ORT}}+1\right]\right.$ istatistiğinin ( $\mathrm{T}-$ 1) serbestlik derecesinde asimptotik olarak ki-kare dağılımına sahip olduğunu göstermiştir.

\section{Frees (1995) Yatay Kesit Bağımlıı̆̆ı Testi}

Frees (1995) karesi alınmış sıralama korelasyon katsayılarının toplamına dayanan bir istatistik önermiştir;

$$
R^{2}{ }_{O R T}=\frac{2}{N(N-1)} \sum_{i=1}^{N-1} \sum_{j=i+1}^{N} \hat{r}^{2}{ }_{i j}
$$

Frees (1995) çalışmasında özellikle şunu göstermektedir: 


$$
F R E=N\left(R_{\text {ORT }}^{2}-(T-1)^{-1}\right) \stackrel{d}{\rightarrow} Q=a(T)\left(x_{1, T-1}^{2}-(T-1)\right)+b(T)\left(x_{2, \frac{T(T-3)}{2}}^{2}-\frac{T(T-3)}{2}\right)
$$

Denklemde $x_{1, T-1}^{2}$ ve $x_{2, \frac{T(T-3)}{2}}^{2}$ sirasiyla (T-1) ve (T(T3)/2) serbestlik derecesinde birbirini etkilemeyen $x^{2}$ rassal değişkenleridir. Frees istatistiği ki-kare dağ1lımlı iki rassal değişkenin (ağırlıklı) toplamına eşit olan Q dağılımı sergiler.

\section{Panel Veri Modellerinde Birim Kök Testi}

Bir zaman serisinin ekonometrik analizi yapilmadan önce serinin durağan olup olmadığına bakılması gerekir. Durağan olmayan serilerle yapilan ekonometrik analizler standart $\mathrm{t}, \mathrm{F}$ testleri ile $\mathrm{R}^{2}$ değerlerinin sapmalı sonuçlar vermesine yol açarak sahte regresyon olarak bilinen yanıltıcı sonuçlara ulaşılacaktır (Tatoğlu, 2013, s.199). Zaman serisinin durağan olup olmadığının araştırması birim kök testleriyle yapılır. Bu çalışmada yatay kesit bağımlılı̆̆ını dikkate alan Pesaran (2007) tarafından öne sürülen CADF testinden yararlanılmıştır.

\section{Pesaran (2007) Birim Kök Testi}

Pesaran (2007) faktör yüklemesini tahmin etmekten ziyade yatay-kesit bağımlılığından kurtulmanın daha basit bir yolunu önermiştir. Onun yöntemi gecikmeli yatay-kesit ortalaması olan normal ADF regresyonunun genişletilmiş halidir ve yöntemindeki birincil farklılık ise tek faktör model vasıtasıyla ortaya çıkan yatay-kesit bağımlılı̆̆ını tespit etmektir. Pesaran tarafından öne sürülen bu yöntem Yatay-kesit Genişletilmiş Dickey-Fuller (CADF) test olarak adlandırılır. Basit bir CADF regresyonunun gösterimi şöyledir (Baltagi, 2007, s.249):

$$
\Delta y_{i t}=a_{i}+p^{*}{ }_{i} y_{i, t-1}+d_{0} \bar{y}_{t-1}+d_{1} \Delta \bar{y}_{t}+\varepsilon_{i t}
$$

$\bar{y}_{t}, \mathrm{t}$ zamandaki tüm $\mathrm{N}$ gözlemlerin ortalamasıdır. Gecikmeli yatay-kesit ortalaması ve onların birinci farkları bir faktör yapısı kanalıyla yatay kesit bağımlılığını izah eder. Hata teriminde veya faktörde serisel korelasyon varsa regresyon tek değişkenli analizde olduğu gibi genişletilir, fakat hem $\mathrm{y}_{\mathrm{it}}$ hem de $\bar{y}_{t}$ 'nin gecikmeli birinci farkları modele eklenir ve ortaya çıkan yeni regresyon modeli şöyle olur (Baltagi, 2007, s.249):

$$
\begin{aligned}
\Delta y_{i t}= & a_{i}+p^{*}{ }_{i} y_{i, t-1}+d_{0} \bar{y}_{t-1}+\sum_{j=0}^{p} d_{j+1} \Delta \bar{y}_{t-j}+ \\
& \sum_{k=1}^{p} c_{k} \Delta y_{i, t-k}+\varepsilon_{i t}
\end{aligned}
$$

Artış derecesi bilgi kriterine veya ardışık testlere göre belirlenebilir. Paneldeki her bir yatay-kesit i için CADF regresyonu tahmin edildikten sonra Pesaran, Yatay Kesit Açısından Genişletilmiş IPS (CIPS) istatistiğini elde etmek için gecikmeli değerler üzerindeki $\left(\mathrm{CADF}_{\mathrm{i}}\right) \mathrm{t}$-istatistiklerinin ortalamasını alır (Baltagi, 2007, s.250):

$$
C I P S=\frac{1}{N} \sum_{i=1}^{N} C A D F_{i}
$$

Çeşitli deterministik terimler için CIPS istatistiğinin kritik değerleri Pesaran (2007) tarafından tablolaştırılmıştır.

\section{Panel Eşbütünleşme Testleri}

\section{Westerlund (2007) Panel Eşbütünleşme Testleri}

Westerlund (2007), Pedroni eşbütünleşme testlerinin eksikliklerini gideren hata düzeltme terimine dayal1 dört adet panel eşbütünleşme testi geliştirmiştir. Regresyon modelinden elde edilen hata terimlerine dayalı yaklaşıma sahip Pedroni eşbütünleşme testlerinde, düzeydeki verilerin uzun dönem eşbütünleşme vektörü birinci farkı alınmış değişkenlerin kısa dönem ayarlama hızı sürecine eşittir. Kremers, Ericsson ve Dolaro (1992) tarafından ortak çarpan kısıtlaması (common factor restriction) olarak adlandirılan bu durum Pedroni gibi hata düzeltme modeline dayalı testlerin gücünü düşürür ve teoride değişkenler arasında eşbütünleşmenin olduğu güçlü bir şekilde ileri sürülmesine karşın eşbütünleşmenin olmadığ1nı belirten sıfır hipotezinin reddedilememesine yol açar (Westerlund, 2007, s.710; Nazlıŏlu, 2010, s.94). Monte Carlo Simülasyon yöntemi sonucunda edinilen bulgular ışığında bu dört yeni test Pedroni (2004) gibi hata terimine dayalı testlerden daha güçlü olup 
iyi düzeyde doğruluk verir. Bununla birlikte bu test yatay kesit bağımlılığı varsa özçıkarım (bootstrap) testleri sonucunda elde edilen dirençli olasılık değerlerini (robust p-values) sunar (Büberkökü, 2014, s.129).

Westerlund (2007, s.715 - 718) hata düzeltme modeline dayalı dört adet panel eşbütünleşme testini sunmuştur. Bunlardan ikisi grup ortalama istatistikleri olarak adlandırılırken diğer ikisi panel istatistikleri olarak adlandırılır.

Grup ortalama istatistikleri şu şekilde hesaplanır:

$$
G_{\tau}=N^{-1} \sum_{i=1}^{N} \frac{\hat{a}_{i}}{\operatorname{SE}\left(\hat{a}_{i}\right)}
$$

ve

$$
G_{\alpha}=N^{-1} \sum_{i=1}^{N} \frac{T \hat{a}_{i}}{\hat{a}_{i}(1)}
$$

Denklemde $S E\left(\hat{a}_{i}\right), \hat{a}_{i}$ 'nin standart hatasını gösterir.

Yukarıdaki grup ortalama istatistikleri için sıfır hipotezi bütün yatay kesiler için eşbütünleşme yoktur $\left(\alpha_{i}=0\right)$ şeklinde tanımlanırken ve alternatif hipotezi ise bazı yatay kesitler için eşbütünleşme vardır $\left(a_{i}<0\right)$ şeklinde tanımlanır (Nazlığlu, 2010, s.94).

Panel istatistiklerinin hesaplanma şekli ise şu şekildedir:

$$
P_{\tau}=\frac{\hat{\alpha}}{S E(\hat{\alpha})}
$$

ve

$$
P_{\alpha}=T \hat{\alpha}
$$

Yukarıdaki panel istatistikleri için sıfır hipotezi bütün yatay kesitler için eşbütünleşme yoktur $\left(\alpha_{i}=0\right)$ şeklinde tanımlanırken ve alternatif hipotez ise bütün yatay kesitler için eşbütünleşme vardır $\left(\alpha_{\mathrm{i}}=\alpha<0\right)$ şeklinde tanımlanır (Nazlıoğlu, 2010, s.95).

\section{Havuzlanmış Ortalama Grup Tahmincisi (PMGE) ve Ortalama Grup Tahmincisi (MGE)}

Panel veri modellerini tahmin etmek için genellikle iki tahmin yöntemi kullanılır. İlki (ortalama grup tahmincisi), paneldeki her grup için ayrı tahminle- rin ortalamasından oluşur. Pesaran ve Smith (1995)'e göre, parametrelerin ortalaması alınarak yapilan bu tahminler tutarlıdır. Pirotte (1999), ortalama grup tahmincisinin geniş bir örneklem boyutu için etkin uzun dönem tahmin edicileri sunduğunu göstermiştir. Bu tahminci parametrelerin gruplar arasinda serbestçe bağımsız olmasına izin verirken gruplar arasındaki olası homojenliği göz önüne almaz. Sıklıkla kullanılan diğer yöntemler rassal veya sabit etkiler ile GMM'dir. Bu modeller, parametrelerin ülkeler arasında aynı olmasını zorlarken özellikle zaman süresi çok uzun olduğunda tutarsız ve yanıltıcı uzun dönem katsayılarına neden olabilmektedir (Bangake ve Eggoh, 2012, s.11).

Pesaran vd. (1999), ülkeler arasında uzun dönem katsayıların aynı olmasını kısa dönem parametrelerin ise gruplar arasında farklı olmasını sağlayan bir ara tahminciyi önermiştir. PMGE'nin bir avantajı, kısa dönem dinamik özelliklerin ülkeden ülkeye farklılık göstermesine ve uzun dönem katsayıların ise aynı olmasına izin verebilmesidir. Ayrıca, Dinamik EKK (DOLS) ve Tam Düzeltilmiş EKK (FMOLS) 'nin aksine, PMG tahmincisi, kısa ve uzun dönem arasındaki ayarlama dinamiğini öne çıkarır.

MG ve PMG tahmincileri arasında seçim yapmada Hausman (1978) testi kullanılabilir (Erdem vd., 2010, s.376). Hausman testine göre sıfır hipotezi altında uzun dönem katsayıları homojendir. Uzun dönem homojenliği altında PMG ve MG tahmincileri tutarlı olmasına karşın sadece PMG tahmincisi etkindir.

Çalışmada $t=1995, \ldots, 2013$ ve $i=1,2,3, \ldots, 23$ şeklinde olup trendsiz iki farklı hata düzeltme modeli kurularak uzun ve kısa dönem parametreleri tahmin edilmeye çalışılmış ve gecikme sayılarının belirlenmesinde AIC’e göre seçim yapılmıştır;

$$
\begin{aligned}
\text { Model 1: } & \Delta \ln (\text { kbgsyih })=\emptyset_{i} \ln \left(\text { kbgsyih }_{i t-1}+\right. \\
& \beta_{i}^{\prime} \ln (r d)_{i t}+\sum_{j=1}^{p-1} \lambda_{i j} \Delta \ln (\text { kbgsyih })_{i t-j}+ \\
& \sum_{j=0}^{q-1} \delta_{i j} \Delta \ln (r d)_{i t-j}+\varepsilon_{i t}
\end{aligned}
$$

$$
\begin{aligned}
\text { Model 2: } & \Delta \ln (\text { kbgsyih })=\emptyset_{i} \ln (\text { kbgsyih })_{i t-1}+ \\
& \beta_{i}^{\prime} \ln (\text { pat })_{i t}+\sum_{j=1}^{p-1} \lambda_{i j} \Delta \ln (\text { kbgsyih })_{i t-j}+ \\
& \sum_{j=0}^{q-1} \delta_{i j} \Delta \ln (\text { pat })_{i t-j}+\varepsilon_{i t}
\end{aligned}
$$




\section{Ampirik Bulgular}

\section{Yatay Kesit Bağımlılığı Test Sonuçları}

Tablo 4'te görüldügüu üzere Model 1 ve Model 2 kullanılarak yapılan yatay kesit bağımlılık test sonuçları $\% 1$ anlamlılık düzeyinde yatay kesit bağımlılığının olmadığı boş hipotezini reddeder. Friedman, Frees ve Pesaran yatay kesit bağımlılık test sonuçları yatay kesit birimleri arasında güçlü bir ilișkinin olduğuna yönelik kanıtları sunar. Bu yüzden serilerin birbirinden bağımsız olduğunu öne süren sıfır hipotezi $\left(\mathrm{H}_{0}\right)$ reddedilerek Model 1 ve Model 2 için değişkenler arasında yatay-kesit bağımlılı̆̆ın olduğu kabul edilir.

Tablo 4. Yatay Kesit Bağımlıığı Test Sonuçları

\begin{tabular}{|c|c|c|}
\hline \multicolumn{3}{|c|}{ Model 1 (sabit etkiler tahmincisi ile): $\operatorname{lnkbgsyih}_{i t}=\alpha+\beta_{1} \ln r d_{i t}+u_{i t}$} \\
\hline Test & İstatistik Değeri & Olasılık Değeri \\
\hline Friedman & 263.772 & $0.0000 *$ \\
\hline Frees & 12.963 & $0.0000 *$ \\
\hline Pesaran CD & 31.488 & $0.0000 *$ \\
\hline \multicolumn{3}{|c|}{ Model 1 (rassal etkiler tahmincisi ile): $\operatorname{lnkbgsyih}_{i t}=\alpha+\beta_{1} \operatorname{lnr}_{i t}+u_{i t}$} \\
\hline Test & İstatistik Değeri & Olasılık Değeri \\
\hline Friedman & 263.923 & $0.0000 *$ \\
\hline Frees & 12.972 & $0.0000 *$ \\
\hline Pesaran CD & 36.773 & $0.0000^{*}$ \\
\hline \multicolumn{3}{|c|}{ Model 2 (sabit etkiler tahmincisi ile): $\operatorname{lnkbgsyih}_{i t}=\alpha+\beta_{1} \operatorname{lnpat}_{i t}+u_{i t}$} \\
\hline Test & İstatistik Değeri & Olasılık Değeri \\
\hline Friedman & 231.518 & $0.0000 *$ \\
\hline Frees & 10.894 & $0.0000^{*}$ \\
\hline Pesaran CD & 31.977 & $0.0000 *$ \\
\hline \multicolumn{3}{|c|}{ Model 2 (rassal etkiler tahmincisi ile): $\operatorname{lnkbgsyih_{it}}=\alpha+\beta_{1} \operatorname{lnpat}_{i t}+u_{i t}$} \\
\hline Test & İstatistik Değeri & Olasılık Değeri \\
\hline Friedman & 250.687 & $0.0000 *$ \\
\hline Frees & 12.130 & $0.0000 *$ \\
\hline Pesaran CD & 34.799 & $0.0000 *$ \\
\hline \multicolumn{3}{|c|}{ Frees Q Dağılımı Kritik Değerleri } \\
\hline $\begin{array}{l}\alpha=\text { 0.10: } 0.1360 \\
\boldsymbol{\alpha}=\mathbf{0 . 0 5 :}: 0.1782 \\
\boldsymbol{\alpha}=\mathbf{0 . 0 1 :} 0.2601\end{array}$ & & \\
\hline
\end{tabular}

Not: \%1 düzeyinde istatistiki olarak anlamlılık * işareti ile gösterilmiştir.

\section{Pesaran (2007) Panel Birim Kök Test Sonuçları}

Tablo 5, Pesaran (2007) panel birim kök testine ait sonuçları sunar. Sabit ve trendsiz Pesaran test sonuçlarına göre doğal logaritması alınmış kişi başına düşen gayri safi yurtiçi hâsıla, Ar-Ge harcamaları ve patent başvuru sayısına ait panel verileri için sıfır hipotezi düzeyde reddedilemez. Fakat serilerin birinci farkı alındığında sıfır hipotezi reddedilir. Bu sonuçlar güçlü bir şekilde değiş̧kenlerin düzeyde durağan olmadığını fakat birinci farklarında durağan olduğunu gösterir. Sabit ve trendin dâhil edildiği Pesaran testi- ne göre kişi başına düşen gayri safi yurtiçi hâsıla ve patent başvuru sayısı serisi düzeyde birim köke sahip değilken, Ar-Ge harcamaları serisinin birinci fark1 alınarak durağanlaştırılmıştır. Sabit ve trendsiz Pesaran test sonuçları temel alınarak bütün değişkenlerin aynı düzeyde bütünleşik (I(1)) olduğu tespit edilmesiyle kişi başına düşen gayri safi yurtiçi hâsıla ile ArGe harcamaları ve kişi başına düşen gayri safi yurtiçi hâsıla ile patent başvuru sayıları arasındaki uzun dönemli ilişkiyi incelemek için Westerlund panel eşbütünleşme testleri uygulanacaktır. 
Tablo 5. Pesaran Birim Kök Test Sonuçları

\begin{tabular}{|c|c|c|c|c|}
\hline & \multicolumn{2}{|c|}{$\begin{array}{c}\text { Pesaran (2007) } \\
\text { (sabit) }\end{array}$} & \multicolumn{2}{c|}{$\begin{array}{c}\text { Pesaran (2007) } \\
\text { (sabit ve trendli) }\end{array}$} \\
\hline & $\begin{array}{c}\text { CIPS İstatistik } \\
\text { Değeri }\end{array}$ & Olasılık Değeri & $\begin{array}{c}\text { CIPS İstatistik } \\
\text { Değeri }\end{array}$ & Olasılık Değeri \\
\hline$(\text { Lnkbgsyih })_{i t}$ & -1.934 & 0.181 & -2.731 & $0.018^{*}$ \\
\hline$\Delta(\text { Lnkbgsyih })_{i t}$ & -2.418 & $0.001^{*}$ & - & - \\
\hline$(\text { Lnrd })_{i t}$ & -0.748 & 1.000 & -2.012 & 0.907 \\
\hline$\Delta(\text { Lnrd })_{i t}$ & -2.510 & $0.000^{*}$ & -2.806 & $0.007^{*}$ \\
\hline$(\text { Lnpat })_{i t}$ & -0.326 & 1.000 & -2.724 & $0.020^{* *}$ \\
\hline$\Delta(\text { Lnpat })_{i t}$ & -3.440 & $0.000^{*}$ & - & \\
\hline
\end{tabular}

Not: \%1 ve \%5 düzeyinde istatistiki olarak anlamlılık sırasıyla * ve ** işaretleri ile gösterilmiştir.

\section{Westerlund Panel Eşbütünleşme Test Sonuçları}

Sadece sabit terimin olduğu Pesaran birim kök testleriyle serilerin aynı düzeyde bütünleşik (I(1)) olduğu tespit edildikten sonra yatay kesit bağımlılığını dikka- te alan dört adet istatistiki testlerden oluşan Westerlund (2007) Panel Eşbütünleşme Testleri uygulanmış ve Tablo 6'da panel eşbütünleşme testine ait sonuçlar sunulmaktadır.

Tablo 6. Westerlund Panel Eşbütünleşme Test Sonuçları

\begin{tabular}{|c|c|c|}
\hline \multicolumn{3}{|c|}{ Model 1: $\operatorname{lnkbgsyih}_{i t}=\alpha+\beta_{1} \ln r d_{i t}+u_{i t}$} \\
\hline İstatistik & İstatistik Değeri & $\begin{array}{c}\begin{array}{c}\text { Dirençli Olasılık Değeri (Robust P- } \\
\text { value) }\end{array} \\
\text { (n) }\end{array}$ \\
\hline$G_{t}$ & -2.049 & $0.000^{*}$ \\
\hline$G_{a}$ & -6.595 & $0.000^{*}$ \\
\hline$P_{t}$ & -7.841 & $0.000^{*}$ \\
\hline$P_{a}$ & -6.026 & $0.000^{*}$ \\
\hline \multicolumn{3}{|c|}{ Model 2: lnkbgsyih $_{i t}=\alpha+\beta_{1}$ lnpat $_{i t}+u_{i t}$} \\
\hline İstatistik & İstatistik Değeri & $\begin{array}{c}\text { Dirençli Olasılık Değeri (Robust P- } \\
\text { value) }\end{array}$ \\
\hline$G_{t}$ & -1.911 & 1.000 \\
\hline$G_{a}$ & -7.058 & $0.000^{*}$ \\
\hline$P_{t}$ & -10.897 & $0.000^{*}$ \\
\hline$P_{a}$ & -9.927 & $0.000^{*}$ \\
\hline
\end{tabular}

Not: \%1 düzeyinde istatistiki olarak anlamllık * işareti ile gösterilmiştir

Yatay kesit birimler arasında korelasyon tespit edildiği için Tablo 5'te standart olasılık değerleri yerine özçıkarım (bootstrap) testleri sonucunda elde edilen dirençli olasılık değerleri (robust p-values) verilmektedir.

Tablo 6'daki sonuçlar incelendiğinde Model 1 için dört istatistiğe göre değiş̧kenler arasında eşbütünleşme ilişkisi yoktur sıfır hipotezi reddedilirken Model 2 için ise yalnızca bir istatistik dışında diğer 3 istatistik tarafından sıfır hipotezi reddedilmektedir. Sonuç olarak kişi başına düşen gayri safi yurtiçi hâsıla - Ar-Ge harcamaları, kişi başına düşen gayri safi yurtiçi hâsıla - patent başvuru sayısı arasında eşbütünleşme ilişkisi mevcuttur.

\section{PMGE ve MGE Sonuçları}

Model 1 ve Model 2'de gösterildiği şekilde tahmini yapılan parametrelere ait sonuçlar Tablo 7'de verilir. 
Tablo 7. PMGE, MGE ve Hausman Test Sonuçlar

\begin{tabular}{|c|c|c|c|c|}
\hline \multicolumn{5}{|l|}{ PMGE } \\
\hline \multicolumn{5}{|c|}{ Model 1: ARDL(1, 2) } \\
\hline$\Delta \ln ($ kbgsyih $)$ & Katsayılar & Standart Hata & $\mathrm{Z}$ istatistiği & $P>|z|$ \\
\hline Lnrd & 0.679802 & 0.0638071 & 10.65 & $0.000^{*}$ \\
\hline Hata düzeltme & -0.0866339 & 0.0340713 & -2.54 & $0.011^{*}$ \\
\hline$\Delta \ln (\mathbf{r d})(-1)$ & 0.1152149 & 0.4916129 & 0.23 & 0.815 \\
\hline$\Delta \ln (\mathbf{r d})(-2)$ & 0.1150397 & 0.1669257 & 0.69 & 0.491 \\
\hline \multicolumn{5}{|c|}{ Hausman Testi: prob $>$ ki-kare $=0.8613$} \\
\hline \multicolumn{5}{|c|}{ Model 2: ARDL $(1,1)$} \\
\hline$\Delta \ln ($ kbgsyih $)$ & Katsayılar & Standart Hata & $\mathrm{Z}$ istatistiği & $P>|z|$ \\
\hline Lnpat & 0.8765107 & 0.0730212 & 12.00 & $0.000^{*}$ \\
\hline Hata düzeltme & -0.1326117 & 0.0290508 & -4.56 & $0.000^{*}$ \\
\hline$\Delta \ln ($ pat $)(-1)$ & 0.2698202 & 0.1834831 & 1.47 & 0.141 \\
\hline \multicolumn{5}{|c|}{ Hausman Testi: prob $>$ ki-kare $=0.9233$} \\
\hline \multicolumn{5}{|l|}{ MGE } \\
\hline \multicolumn{5}{|c|}{ Model 1: ARDL $(1,2)$} \\
\hline$\Delta \ln ($ kbgsyih $)$ & Katsayılar & Standart Hata & $\mathrm{Z}$ istatistiğ $\mathbf{i}$ & $P>|z|$ \\
\hline Lnrd & 0.9639681 & 1.386386 & 0.70 & 0.487 \\
\hline Hata düzeltme & -0.2403966 & 0.0600077 & -4.01 & $0.000^{*}$ \\
\hline$\Delta \ln (\mathbf{r d})(-1)$ & 0.4024934 & 0.6231977 & 0.65 & 0.518 \\
\hline$\Delta \ln (\mathbf{r d})(-2)$ & -0.1815841 & 0.3145525 & -0.58 & 0.564 \\
\hline \multicolumn{5}{|c|}{ Model 2: ARDL $(1,1)$} \\
\hline$\Delta \ln ($ kbgsyih) & Katsayılar & Standart Hata & $\mathrm{Z}$ istatistiği & $P>|z|$ \\
\hline Lnpat & 0.8029036 & 0.7248141 & 1.11 & 0.268 \\
\hline Hata düzeltme & -0.206604 & 0.0315289 & -6.55 & $0.000^{*}$ \\
\hline$\Delta \ln ($ pat $)(-1)$ & 0.3152838 & 0.1734214 & 1.82 & $0.069 * *$ \\
\hline
\end{tabular}

Not: \%1 ve \%10 düzeyinde istatistiki olarak anlamllık sırasıyla ${ }^{*}{ }^{* *}$ işaretleri ile gösterilmiştir.

Yukarıdaki sonuçlardan görüldügüu üzere her iki model için Hausman test istatistiğinin değeri ki-kare değerinden büyük çıkmıştır. H_0 Hipotezi altında "uzun dönemde parametreler homojendir" şeklindeki önerme reddedilmemiştir ve bu kapsamda uzun dönem parametrelerini tüm birimler için sabit kabul eden PMGE'nin geçerli olduğuna karar verilmiştir. $\mathrm{Bu}$ yüzden PMGE yöntemi kullanılarak yapılan parametre tahminleri yorumlanmıştır.

Model 1'e ait sonuçlara göre hata düzeltme parametresi (-0.086) negatif ve anlamlıdır, iki değişken arasında (kişi başına düşen gayri safi yurtiçi hâsıla ve Arge harcamaları) uzun dönemli bir ilişkinin mevcut olduğunu işaret eder. Bu aynı zamanda herhangi bir şok meydana geldiğinde kişi basına gayri safi yurtiçi hasılanın yaklaşık \%8'i bir sonraki dönemde düzelerek uzun dönem dengesine yaklaşacağ $\breve{1}_{1}$ anlamına gelir. Ayrıca toplam Ar-Ge harcamalarının uzun dönem parametresi (0.679) istatistiki olarak anlamlı ve işareti beklendiği üzere pozitiftir, fakat kısa dönem parametreleri istatistiki olarak anlamsızdır. Uzun dönemde toplam Ar-Ge harcamalarında \%1'lik artış, kişi başına düşen gayri safi yurt içi hasılayı $\% 0.67$ oranında arttırmaktadır.

Model 2'ye ait sonuçlara bakıldığında hata düzeltme parametresinin $(-0.132)$ negatif ve istatistiki olarak anlamlı olması bir dönemde oluşan dengesizliklerin yaklaşık \%13 oranında bir sonraki dönemde dengeye ulaşacağını belirtir. Bu yüzden kişi başına düşen gayri safi yurt içi hâsıla ile USPTO'ya yapılmış toplam patent başvuru sayıları arasında uzun dönemli bir ilişkinin varlığından söz edilebilir. Bununla birlikte patent başvuru sayılarına ait uzun dönem katsayısı (0.876) pozitif ve istatistiki olarak anlamlıdır, fakat kısa dönem katsayıları ise istatistiki olarak anlamlı değildir. Uzun dönemde USPTO'ya yapılmış toplam patent başvuru sayısında \%1'lik artış, kişi başına düşen gayri safi yurtiçi hasılada \% 0.86 oranında artışa yol açar. 


\section{Sonuç}

$\mathrm{Bu}$ çalışmada; geleneksel inovasyon göstergeleri olarak kabul edilen Ar-Ge harcamalarının ve patent başvuru sayılarının ekonomik büyüme üzerindeki etkisi 1995 - 2013 yıllık verileri kullanılarak seçili 23 OECD ülkesi (Avusturya, Belçika, Kanada, Çek Cumhuriyeti, Finlandiya, Fransa, Almanya, Macaristan, İrlanda, İsrail, İtalya, Japonya, Güney Kore, Meksika, Hollanda, Polonya, Portekiz, Slovakya, Slovenya, İspanya, Türkiye, Birleşik Krallık (İngiltere), ABD) için panel veri analiziyle araştırılmıştır. Bu doğrultuda iki ekonometrik model kurulmuştur. Westerlund Panel Eşbütünleşme Testi sonucunda kişi başına düşen gayri safi yurtiçi hâsıla - Ar-Ge harcamaları, kişi başına düşen gayri safi yurtiçi hâsıla - patent başvuru sayısı arasında eşbütünleşme ilişkisi saptanmıştır. Uzun ve kısa dönemli katsayıları tahmin etmek için kullanılan PMGE ve MGE yöntemleri ile Ar-Ge harcamalarının ve patent başvuru sayılarının sadece uzun dönem katsayıları istatistiki olarak anlamlı çıkmış ve pozitif olduğu bulunmuştur.

Ekonometrik analiz sonucunda elde edilen bulgular ışığıında OECD ülkeleri tarafından yapılan Ar-Ge yatırımlarının artması patent başvurularını daha da hızlandıracak ve böylelikle sürdürülebilir ekonomik büyümenin önü açılacaktır. Bu yüzden uzun dönemde ekonomik büyümeyi sürdürülebilir kılmak için OECD ekonomilerinin Ar-Ge yatırımlarını arttırmaya devam etmesi önemlidir. Sonuç olarak inovasyonun ekonomik büyüme üzerindeki etkilerinin uzun dönemde gözlemlenebilir olması politika yapıcılar tarafından göz önünde bulundurulması gereken bir husus olup Ar - Ge ve inovasyonu teşvik amaçlı tasarlanacak politikaların bu doğrultuda oluşturulmasina dikkat edilmelidir.

\section{Kaynakça}

Aghion, P. \& Howitt, P. (1992). A model of Growth Through Creative Destruction. Econometrica: Journal of the Econometric Society, 60(2), 323 - 351.

Aghion, P. \& Howitt, P. (1999). Endogenous Growth Theory. Cambridge: The MIT Press.

Altıntaş, H. \& Mercan M. (2015). AR-GE Harcamaları ve Ekonomik Büyüme İlişkisi: OECD Ülkeleri Üzerine Yatay Kesit Bağımlılığı Altında Panel Eşbütünleşme Analizi. Ankara Üniversitesi SBF Dergisi, $70(2), 345-376$.
Baltagi, B. (2007). Econometric Analysis of Panel Data. Chichester: John Wiley \& Sons.

Bangake, C. \& Eggoh, J. C. (2012). Pooled Mean Group Estimation on International Capital Mobility in African Countries. Research in Economics, 66(1), 7 - 17.

Breush, T. S. \& Pagan, A. R. (1980). The Lagrange Multiplier Test and Its Applications to Model Specification in Econometrics. The Review of Economic Studies, 47(1), 239 - 253.

Büberkökü, Ö. (2014). Yükselen Piyasa Ekonomilerinde Uluslararası Satın Alma Gücü Paritesi: Panel Koentegrasyon Testlerinden Kanttlar. BDDK Bankacilik ve Finansal Piyasalar Dergisi, 8(1), 117-139.

Coombs, R., Saviotti, P. \& Walsh, V. (1987). Economics and Technological Change. London: Macmillan Education.

Crosby, M. (2000). Patents, Innovation and Growth. The Economic Record, 76(234), 255 - 262.

Dam, M. M. \& Yıldız, B. (2016). BRICS-TM Ülkelerinde Ar-Ge ve İnovasyonun Ekonometrik Büyüme Üzerine Etkisi: Ekonometrik Bir Analiz. Akdeniz İ.I.B.F. Dergisi, 33, 220 - 236.

De Hoyos, R. E. \& Sarafidis, V. (2006). Testing for Cross-Sectional Dependence in Panel-Data Models. Stata Journal, 6(4), 482 - 496.

Devinney, T. M. (1994). Characterising International Patent Behaviour. Australian Graduate School of Management Working Paper, (No: 94 - 024).

Domar, E. D. (1946). Capital Expansion, Rate of Growth, and Employment. Econometrica: Journal of the Econometric Society, 14(2), 137 - 147.

Doruk, Ö. T. \& Söylemezoğlu, E. (2014), Gelişmekte Olan Ülkelerde Ar-Ge'ye Dayalı Büyümenin Varlığının Sinanması. 1. Ulusal Üretim Ekonomisi Kongresi, https://papers.ssrn.com/sol3/papers. cfm?abstract_id=2541083, (20.04.2017).

Erdem, E., Guloglu, B. \& Nazlioglu, S. (2010). The Macroeconomy and Turkish Agricultural Trade Balance with the EU Countries: Panel ARDL Analysis. International Journal of Economic Perspectives, 4(1), $371-379$. 
Frees, E. W. (1995). Assessing Cross-Sectional Correlation in Panel Data. Journal of Econometrics, 69(2), $393-414$.

Freimane, R. \& Balina, S. (2016). Research and Development Expenditures and Economic Growth in the EU: A Panel Data Analysis, Economics and Business, 29(1), 5 - 11.

Friedman, M. (1937). The Use of Ranks to Avoid the Assumption of Normality Implicit in the Analysis of Variance. Journal of the American Statistical Association, 32(200), 675 - 701 .

Genç, M. C. \& Atasoy, Y. (2010). AR\&GE Harcamaları ve Ekonomik Büyüme İlişkisi: Panel Veri Analizi. Bilgi Ekonomisi ve Yönetimi Dergisi, 5(2), 27-34.

Grossman, G. M. \& Helpman, E. (1989). Product Development and International Trade. Journal of Political Economy, 97(6), 1261 - 1283.

Grossman, G. M. \& Helpman, E. (1990). Comparative Advantage and Long-run Growth. The American Economic Review, 80(4), 796 - 815.

Grossman, G. M. \& Helpman, E. (1993). Endogenous Innovation in the Theory of Growth. National Bureau of Economic Research Working Paper, (No. w4527), 1 - 36.

Grossman, G. M. \& Helpman, E. (1997). Innovation and Growth in the Global Economy. Cambridge: MIT Press.

Guo, Y. \& Wang, B. (2013). Study on the Economic Growth of Patent Output in the High-tech Industry. Journal of Management and Sustainability, 3(1), 103 - 107.

Gülmez, A. \& Yardımcıoğlu, F. (2012). OECD Ülkelerinde Ar-Ge Harcamaları ve Ekonomik Büyüme İlişkisi: Panel Eşbütünleşme ve Panel Nedensellik Analizi (1990-2010). Maliye Dergisi, 163, 335 353.

Gürak, H. (2006). Önce Bilgili İnsan Ekonomik Büyüme ve Refahın Gerçek Kaynakları Olan: Üretim Bilgisi (Teknoloji) ve Nitelikli Emek Üzerine, http://www.hasmendi.net/makale_gurak/once_ bilgili_insan.pdf, (17.04.2017).
Harrod, R. F. (1939). An Essay in Dynamic Theory. The Economic Journal, 49(193), 14 - 33.

Hausman, J. A. (1978). Specification Tests in Econometrics. Econometrica: Journal of the Econometric Society, 46(6), 1251 - 1271.

Işık, C. (2014). Patent Harcamaları ve İktisadi Büyüme Arasındaki İlişki: Türkiye Örneği. Sosyoekonomi, 21(21), $69-86$.

İlgün, M. F. (2016). Mali Sürdürülebilirlik: OECD Ülkelerine Yönelik Panel Veri Analizi. Atatürk Üniversitesi İktisadi ve İdari Bilimler Dergisi, 30(1), 69-90.

Josheski, D. \& Koteski, C. (2011). The Causal Relationship between Patent Growth and Growth of GDP with Quarterly Data in the G7 Countries: Cointegration, ARDL and Error Correction Models, https://papers.ssrn.com/sol3/papers.cfm?abstract_ $\mathrm{id}=1921908,(21.04 .2017)$.

Kremers, J., Ericson, N. R. \& Dolado, J. J.(1992).The Power of Cointegration Tests. Board of Governors of the Federal Reserve System, International Finance Discussion Paper, 431, 1 - 31.

Li, J. \& Jiang, Y. (2016), Calculation and Empirical Analysis on the Contributions of R\&D Spending and Patents to China's Economic Growth. Theoretical Economics Letters, 6(6), 1256 - 1266.

Mehran, M. \& Reza, M. (2011). A Comperative Investigation of the Relation of R\&D Expenditures to Economic Growth in a Group of the Less Developed Countries and OECD Countries. Journal of Social and Development Sciences, 2(4), 188 - 195.

Miller, R. L., Benjamin, D. K. \& North, D. C. (2012). The Economics of Public Issues. New Jersey: Pearson.

Nazlığlu, Ş. (2010). Makro İktisat Politikalarının Tarım Sektörü Üzerindeki Etkileri: Gelişmiş ve Gelişmekte Olan Ülkeler İçin Bir Karşılaştırma. (Yayımlanmamış doktora tezi). Erciyes Üniversitesi/Sosyal Bilimler Enstitüsü, Kayseri.

Nazlioglu, S., Lebe,F. \& Kayhan, S.(2011). Nuclear Energy Consumption and Economic Growth in OECD Countries: Cross - Sectionally Dependent Heterogeneous Panel Causality Analysis. Energy Policy, 39(10), 6615 - 6621. 
Özşahin, Ş. \& Gömleksiz, M. (2016), Ekonomik Gelişmişlik ve Ar-Ge Harcamaları: Yükselen Piyasa Ekonomileri Üzerine Panel Eşbütünleşme ve Nedensellik Analizi, Uluslararası Yönetim, Ekonomi ve Politika Kongresi Bildiriler Kitabı, 3702 - 3717.

Pedroni, P.(2004). Panel Cointegration: Asymptotic and Finite Sample Properties of Pooled Time Series Tests with an Application to the PPP Hypothesis. Econometric Theory, 20(3), 597 - 625.

Peng, L. (2010). Study on Relationship between R\&D Expenditure and Economic Growth of China. In Proceedings of the 7th International Conference on Innovation \& Management, 1725 - 1728.

Pesaran, M. H. \& Smith, R. (1995). Estimating LongRun Relationships from Dynamic Heterogeneous Panels. Journal of Econometrics, 68(1), 79 - 113.

Pesaran, M. H., Shin, Y. \& Smith, R. P.(1999). Pooled Mean Group Estimation of Dynamic Heterogeneous Panels. Journal of the American Statistical Association, 94(446) 621 - 634.

Pesaran, M. H. (2004). General Diagnostic Tests for Cross Section Dependence in Panels. CESifo Working Paper Series No. 1229; IZA Discussion Paper No. 1240, 1 - 39.

Pesaran, M. H. (2007). A Simple Panel Unit Root Test in the Presence of Cross - Section Dependence. Journal of Applied Econometrics, 22(2), 265 - 312.

Pirotte, A. (1999). Convergence of the static estimation toward the long-run effects of dynamic panel data models. Economics Letters, 63(2), 151-158.

Romer, P. M. (1990). Endogenous Technological Change. Journal of Political Economy, 98(5, Part 2), $71-102$.

Saini, A. K. \& Jain, S. (2011), The Impact of Patent Applications Filed on Sustainable Development of Selected Asian Countries. International Journal of Information Technology, 3(2), 358 - 364.

Samimi, A. J. \& Alerasoul, S.M. (2009). R\&D and Economic Growth: New Evidence from Some Developing Countries. Australian Journal of Basic and Applied Sciences, 3(4), 3464 - 3469.
Sarafidis, V.,Yamagata, T. \& Robertson, D. (2009). A Test of Cross Section Dependence for A Linear Dynamic Panel Model with Regressors. Journal of Econometrics, 148(2), 149 - 161.

Schmookler, J. (1966). Invention and Economic Growth. Cambridge: Harvard University Press.

Schumpeter, J. A. (1983). The Theory of Economic Development: An Inquiry into Profits, Capital, Credit, Interest, and the Business Cycle. Piscataway: Transaction Publishers.

Sinha, D. (2008). Patents, Innovations and Economic Growth in Japan and South Korea: Evidence from Individual Country and Panel Data. Applied Econometrics and International Development, 8(1), 181-188.

Solow, R. M. (1957). Technical Change and the Aggregate Production Function. The Review of Economics and Statistics, 39(3), 312 - 320.

Svenningsen, J. D. \& Bjørnskov, C. (2015). Does Innovation Really Have an Impact on Economic Growth?. (Unpublished master thesis). Aarhus University/Business and Social Sciences, Aarhus.

Tatoğlu, F. Y. (2013). İleri Panel Veri Analizi: Stata Uygulamalı. İstanbul: Beta Yayıncılık.

Tunalı, Ç. B. (2016). The Effect of Research and Development Spending on Economic Growth in OECD Countries. Journal of Administrative Sciences, 14(27), 59 - 79 .

Türedi, S. (2016). The Relationship between R\&D Expenditures, Patent Applications and Growth: A Dynamic Panel Causality Analysis for OECD Countries. Anadolu University Journal of Social Sciences, 16(1), 39 - 48.

U.S. PATENT AND TRADEMARK OFFICE. (2016). Types of Patents. https://www.uspto.gov/web/offices/ac/ido/oeip/taf/patdesc.htm, (24.04.2017).

Van Den Berg, H. (2001). Economic Growth and Development. Singapore: McGraw - Hill Irwin.

Westerlund, J. (2007). Testing for Error Correction in Panel Data. Oxford Bulletin of Economics and Statistics, 69(6), 709 - 748. 